\title{
Making Music in Bankstown: Responding to Place Through Song
}

\author{
Toby Martin \\ University of Huddersfield \\ toby.martin@hud.ac.uk
}

\begin{abstract}
Two songs - "Dreams In German" and "Olive Tree" — are presented here as an attempt to explore how composition, arrangement, and recording of popular music can respond to a specific place, in this case, the Sydney suburb of Bankstown. Through lyrics, song structures, instrumentation, and recording, these songs try to capture the sounds and stories of a multicultural, multiphonic urban area in the twenty-first century. The accompanying short essay contextualizes these compositions. It outlines the research aims and methodologies used in trying to achieve this. It also places the research within scholarship on popular music and place, and intercultural music collaborations. Its conclusions are that listening is important in responding to place and that music and song has a special role to play in a response to place.
\end{abstract}

KEYWORDS: songwriting, place, intercultural

The compositions that are part of this study can be found here:

"Dreams in German":

https://soundcloud.com/toby_martin_solo/dreams-in-german

https://open.spotify.com/track/3cPl6yF3yvFwxgDN18k9U6

"Olive Tree":

https://soundcloud.com/toby_martin_solo/olive-tree

https://open.spotify.com/track/40lOQ6yE82EXRWOGxc8NkC

\section{Introduction}

In 2013 and 2014, Urban Theatre Projects', based in the Sydney suburb of Bankstown, invited me to take part in their Practice and Participate program, which placed artists in the front gardens of local residents, or outside local businesses. I had two locations: the first an unoccupied house across the road from my host's 
home; the second outside a mixed business and coffee shop. For approximately five weeks, over the course of two years, I effectively used these locations as studios from which to generate lyrical and musical material for new songs. These songs were eventually recorded with a group of musicians of diverse backgrounds from Bankstown's surrounding area and released as an album, Songs From Northam Avenue (Northam Avenue being one of the locations I wrote in: Martin 2017). Two of the songs from that album "Dreams in German" and "Olive Tree" are available here as representative of the album, and of the results of my research into songwriting and recording processes.

The research question that underpinned my work in the studios - both the studios on the street and the literal recording studio - was how to respond to a place in song. This short essay, then, provides a framework for ways of looking at the research that informed the final recorded music. It suggests that to represent a place through song, artists may need to take a holistic approach, one that includes lyric writing, harmonic composition, instrumentation and arrangement, and production and recording. It also suggests that one approach to responding to place - especially as an outsider in that place - is careful and long-term listening. In my case, this meant listening to stories from people in those places and the ways in which these stories were constructed and told. It also meant listening to the collaborating musicians - listening to the music they play and the ways they choose to compose and record.

There are numerous examples of albums that seem to explicitly set out to capture the feel, or different stories from, a particular place. A proper analysis of these would be a subject of a much longer essay, however it is worth briefly looking at some notable examples. Sufjan Stevens's Michigan (2003) and Illinois (2005) feature stories and history from these American states, Gabriel Kahane's The Ambassador (2014) was written in various sites around Los Angeles and seek to tell stories from that city, while the songs on Bruce Springsteen's Nebraska (1982) evoke workingclass suburban or rural neighbourhoods in the mid-west and rust belt (not necessarily Nebraska). In the UK, The Magnetic North have attempted to capture a sense of the Orkney islands (2012), and the northern town of Skelmersdale (2016). Richard Hawley frequently returns to the urban landscape of Sheffield in work such as Coles Corner (2005), while Darkstar's 2015 album Foam Island was about the West Yorkshire town of Huddersfield and featured sampled quotes from local residents with instrumental electronica. In Australia, You Am I's Hourly Daily (1996) was presented as a day in the life of inner-city Sydney.

One of the ways in which Songs From Northam Avenue distinguishes itself from the above records is through a process that was built around discovering ways in which an outsider to a place could collaborate with insiders, finding a space "inbetween" (Trulsson and Burnard 2016). Two particular ways in which this happened was through lyrics that were often built up from verbatim snatches of dialogue with my hosts, and through capturing the performances of local collaborating musicians. Also, popular music writing tends to talk about albums that deal explicitly with place, such as the ones listed above, by focussing on lyrics. ${ }^{2}$ What I want to highlight here is how approaches to composition, instrumentation and recording may also play a part.

The connections between music and place have been much discussed in the field of popular music studies in recent years. This scholarship has largely been written by musicologists, sociologists, or ethnographers, rather than musicians or composers. Approaches to music and place are far too varied to discuss in detail here, but include studies of the ways in which place is produced through the consumption and performance of music (Cohen 1995; Le Menestrel and Henry 
2010; Stokes 1994), ways in which music operates as a psychogeography of landscape (Mitchell 2013), considerations of globalization and translocalism and their effects on particular musical scenes (Mitchell 1996; Stokes 2004), and ways in which music helps cultural groups negotiate the everyday life of their homeplaces (Bennett 2005). This essay, and the associated recordings, offer a composer's perspective on the relationship between a sense of place and musicmaking that will hopefully enrich the conversation around popular music and place.

\section{Bankstown - some background}

Bankstown is a suburb about forty minutes by train southwest of Sydney's central business district, and part of the region known as Greater Western Sydney. For many Australians, particularly Sydneysiders, Bankstown is synonymous with a strong working-class identity. Paul Keating, Australian Prime Minister from 19911996, was known as the 'boy from Bankstown', indicating the way in which he was a working-class success story. Historically a working-class identity has also been a white-Anglo identity, however increasingly through the twentieth and twenty-first centuries Bankstown has become home to new migrant communities from outside western Europe. From the 1970s on, it became a place where refugees from southeast Asia, particularly Vietnam, ended up settling after fleeing from war-torn regions. From the 1980s, it has increasingly become home for Lebanese, Iraqi and Syrian families also seeking a better life away from troubled parts of the world. In 2016, 55\% of Bankstown residents spoke a language other than English at home, primarily Vietnamese and Arabic. ${ }^{3}$ Greater Western Sydney also has the highest concentration of Indigenous people in Australia. ${ }^{4}$ Consequently, Bankstown is popularly conceived both by insiders and outsiders as a 'multicultural' suburb, and often as an example of that policy's success. However, Bankstown has also been repeatedly misrepresented by Sydney's tabloid media as a place populated by ethnic-based criminal gangs and, following 9/11, as a source of Islamic fundamentalism (Ahmad: 2013). ${ }^{5}$ Whether through class or ethnicity, western Sydney is often conceived of as Sydney's 'other', reinforcing the idea that 'multiculturalism' is often considered 'other' to the norm (see Simic 2008).

My own relationship with Bankstown is important to acknowledge. While the suburb was the first Australian home for my grandfather (a German/Hungarian Jew), my grandmother (British) and their infant son (my father) after arriving by boat in Sydney in 1948, they only stayed there two years before moving on, eventually to Melbourne. Having spent most of my adult life in the inner-west of Sydney, I am very much an outsider to Bankstown (see Smith 2017), and not just geographically. A native English speaker, from the dominant white-Anglo cultural group, and middle class, I bring with me a significant degree of privilege when I work with people in Bankstown. There are measurable discrepancies between income and status between western Sydney and its eastern neighbours - the fact that 'western Sydney' has its own place name is idiomatic of that - and there is a strong sense of a border between western and eastern Sydney. Part of this project was looking for ways in which those borders could be reached across and used as a dynamic place to create music. 


\section{Methodologies}

\section{Composition}

The aim of the lyrics was to poetically re-cast stories and anecdotes I heard while working in Bankstown. Therefore, the material for many of the lyrics came from conversations I had with the people who were my residency hosts, as well as their neighbours, families and friends. My first host was of Anglo-Scottish ancestry, who was born in Bankstown in the 1930s, was raised in the weatherboard house he had lived in ever since. My second host was originally from Lebanon and, after a varied life, now owned and ran a corner store and coffee shop. I took notes following some of our conversations, trying to record verbatim phrasing where possible. As poet Simon Armitage has noted in writing lyrics for documentary musicals, distinctive speech patterns and mannerisms are useful for conveying a credible sense of a subject's voice (Paget and Roscoe 2006). I wove stories and phrases that seemed to have especially vivid detail or emotionality with other details about the neighbourhood - about how the houses looked, or what was in the newspapers, or the sound of a car radio as it drove past, or what was growing in people's gardens. I also drew in relevant anecdotes or stories from my own experiences away from Bankstown. These woven stories tended to be written separately from the music in a stream-of-consciousness technique. These word sketches were then adapted into song lyrics. For instance, the song "Dreams In German" is an account of my first host's working life, the death of his wife at the age of his retirement, and the sacred place his garden occupies in his life. I adapted ways in which he talked about these things, but re-staged them as dramatic and evocative moments. For example: "I pushed the door aside, I took a walk outside/ and I breathed deep of the garden, the tomato leaves and jasmine" (2:42-2:52).

Many of the conversations I had with my second host were about his experience of a migrant in a new country. The song "Olive Tree" began as an anecdote that he told me. He described going to rugby league games with his sons and when the national anthem was played his sons being reluctant to stand and sing. This made him angry as he considered Australia to be a good country that he had made a life in, and that there was nothing in Lebanon for them. I re-staged this story into the line on "Olive Tree": "I tell my children when they're listening, 'this is now your home/learn the words to the national anthem, sing along'" (0:30-0:45). The imagery on "Olive Tree" also includes stories that were not from my time in Bankstown. For instance, the anecdote about the central character being forced to kiss the flag (2:22-2:38) is based around stories that circulated following the socalled Cronulla Riots of 2005, which was a violent pogrom against youth of middleeastern descent in the Sydney beachside suburb. Ghassan Hage has written about both these issues - about the ways in which second-generation migrants are often more openly critical of their country than their parents, and about the ways in which reactionary culture considers this generation to be overassimilated — by behaving too much like Australians and thus transgressing their role as migrants (Hage 2011). Hage's writing provided a framework through which to view some of the stories I heard. The title of "Olive Tree" was inspired by a tree growing in the front yard of a neighbour of a nearby house and the care with which it was tended (0:14-0:21 and 5:33-5:48) and is symbolic of the themes explored in the song. The lyrics to these songs draw on many sources, and the line between documentary and fiction is blurry. This blurred line is a conscious way to develop connections between people and images. It is important to note that both my hosts were people whom I would not have met had I not been doing research. We were different through background, experience and age. However, through sharing stories I began to see 
all sorts of commonalities between us - especially our relationships to our families - and ways in which these stories could merge as a collection of songs.

"Olive Tree" and "Dreams in German", and indeed the whole album, have a relatively large number of words and seek to tell a direct narrative story using a saturation of specific and everyday imagery. It seemed to become important to the project for the lyrics to be foregrounded, so they could be grasped on first listen, and hold the listener's attention, rather like a short story might. In order to do this the musical architecture of the songs was minimal and repetitive in order to create an open space for the lyrics to live in. There are relatively few chord changes, relatively few sections, and minimal deployment of dynamics. In "Dreams in German", for instance, there are just two sections, using two chords each, repeated twice. Similarly, "Olive Tree" stays almost exclusively focused on E minor, moving to B major briefly at end of each phrase. The harmonic minimalism also reflects something of the physical spaces of Bankstown. In particular, the spaciousness of Bankstown's suburban streets, its consistent single or double-storey architecture, quarter-acre blocks, wide nature strips, and the consequently often empty and quiet streets of the residential areas.

\section{Instrumentation and Arrangement}

Away from the quieter residential streets, the aural experience of downtown Bankstown is loud and multiphonic. Street performers near the train station play the erhu (a Chinese violin), Vietnamese pop music spills out of bakeries, pumping beats with Arabic inflections blast out of car stereos. Voices speak various dialects of Arabic, Chinese, Vietnamese, and English. Hotted-up car engines rev down South Chapel Road. Lorikeets and cockatoos screech overhead. It is common to hear places like Bankstown described as multicultural. However, as Bayley and Nooshin (2017) have observed, to affix a prefix to the word cultural is to assume that there might be an alternative to multi-ness, that there is an assumption of otherness embedded in the word. But what culture is not 'multi'? To my ears, Bankstown's soundscape was unavoidably multi, but more so it was a local, suburban, Australian sound.

My aim was to capture this richness of sound and culture through instrumentation. Through various community groups in southwest Sydney I met and played with musicians from a variety of backgrounds. By the time we came to record an album the ensemble had solidified. The core group was Alex Hadchiti playing oud (a lute-like instrument found across the Middle East), Mohammed Lelo playing qanun (a plucked dulcimer, from the Mediterranean and Middle East), and Dang Lan playing đàn bầu (monochord), đàn tranh (zither), sênh tiền (coin and clapper) and teacup percussion. These three musicians were all refugees or migrants from war-torn regions. Lan had escaped Saigon in 1975 and made her way to Australia. Alex had left Lebanon in the 1980s. Mohammed had migrated from Iraq, via Qatar, in the mid-2010s. All musicians were now residents of western Sydney and played regularly within their cultural communities. Their playing features heavily throughout the record. For instance, "Olive Tree" features the qanun, the đàn tranh and the oud throughout, as well as backing vocals from these three musicians, while on "Dreams In German" the qanun mirrors the electric guitar throughout the song and plays a solo between the verses (1:19-1:50). This core group also featured Bree van Reyk, who played drums and percussion and arranged and produced the album. Bree is a western-contemporary musician and composer based in inner-city Sydney. Elsewhere on the record there are cameo performances from other artists, such as Maroun Azar originally from Lebanon, playing mijwiz (a 
reed instrument made from bamboo, common across the middle east), as well as two bass players Zoe Hauptmann and Matthew Steffen, two vocalists Holly Throsby and Sarah Blasko (who sings on "Dreams in German"), and a guitarist Cameron Emerson-Elliott, all from the western indie rock, jazz and contemporary music scenes based around inner-city Sydney.

Numerous collaborations have attempted to fuse western and non-western instruments and song forms. Some more famous include Paul Simon's Graceland (1986), Ry Cooder's collaborations with Vishwa Mohan Bhatt on Meeting By The River (1993), and Ali Farka Toure on Talking Timbuktu (1994) (see Plasketes 1995), and Sirocco's 1989 album Port of Call (see Mitchell 1996). Many so-called world music albums are collaborations between people from different parts of the world, but with a shared musical language (west African and American blues guitar styles, for instance). Our album was made by people who lived in the same city, but with different musical traditions. While the rhetoric around many albums that fuse styles emphasizes points of musical commonality, or breaking down boundaries, we were keen not to erase difference in the song arrangements. We also wanted to avoid simply tacking on non-western instrumentation to western harmonic structures and musical traditions. World music and western policies of multiculturalism have been justly criticized for adding exotic elements of other cultures to the entrenched value of mainstream Anglo-British culture (Hage 1997; hooks 1992; Kassabian 2004; Mitchell 1996). Bankstown is a contested space, with varying claims of cultural ownership and rights. Different sounds and cultures bump up against each other, yet live alongside each other. We wanted to preserve this feeling of multiple voices in the song arrangements in order to best capture the feeling of Bankstown as lived experience.

In order to achieve this, the musicians needed to fully inhabit the songs. Consequently, we rehearsed on and off for a period of ten months, and by ear with no written notation (see Klopper 2010 for reflection on this process elsewhere). These were deliberate strategies to encourage the musicians to find their way in the song through improvisation and familiarization with the material. Lan spent some time exploring the tunings of the đàn tranh, which used radically different pitch systems to the western and Arabic instruments, and we all needed time to familiarize ourselves with the new combinations of microtonal inflections. There were several musical outcomes to this combination of time and improvisation. One outcome was that pre-existing vocal melodies were varied and repeated by the instruments, especially the qanun (for example "Olive Tree" 3:52-4:00). This idea was instigated by Alex and Mohammed and is a 'call and response' method common to Arabic musicians, whereas the western, indie rock tradition may have built different but complimentary parts. Another outcome was that the various instruments played the role of differing, almost competing voices, rising in and out of the sonic picture. This happens throughout "Olive Tree" (especially around 3:33). In both outcomes, the musicians brought their performances to the songs, although adapted them to fit.

As well as rehearsing for a long period, we also took part in other musical or social activities together. For instance, Mohammed and I performed at a wedding, and I learnt a Vietnamese song from Lan. We also shared meals together in each other's houses and met and talked about each other's families and friends. The social dimension to our relationships helped to establish trust and understanding between us. Such qualities are often vital for any musical collaboration (Spitzer 2017). In collaborations that reach across different cultures, it becomes vital. Bartleet has written about the role of love in intercultural arts, and the affection we developed for each other was a form of "love across difference" (Bartleet 2016: 
100). By playing together, we were also practicing "artistic citizenship", a way of knowing the world and knowing difference through artistic practice (Carfoot 2016: 225). I would argue that socializing and developing our interpersonal relationships were as important to the development of the album as rehearsing. Ultimately, in developing the palette of sounds that constituted this album, it was important for us as musicians to listen - both to each other's performance choices, but also to each other's cultural backgrounds and lives.

\section{Recording}

Rehearsals for the album took place in the musicians' houses in western Sydney and in a rehearsal studio at Urban Theatre Projects in Bankstown. While the album was recorded in a recording studio in Sydenham (in Sydney's inner west), the album's producers (Bree van Reyk and myself), the engineer (Bob Scott) and the musicians wanted as much as possible to re-create the spontaneous and improvisatory feel of rehearsals. Consequently, we recorded live and in real time as much as possible, including lead vocals. For example, "Olive Tree" is entirely live, with the exception of the backing vocals. This is unusual in the world of pop and rock, which usually focusses on building up texture through overdubbing. However, live recording seemed to be more familiar and comfortable to Alex, Mohammed and Lan, so once again we adapted the project to suit varying performance styles. (It is also worth noting that live recording is also more common in western classical music, which was part of Bree and Bob's background, and thus is another example of the intercultural nature of the project).

As well as creating the feel of spontaneous communication through use of time, we also attempted this through use of space. For instance, on several songs, including "Olive Tree", the qanun, oud, đàn tranh and double bass were all positioned in the same live room. This was not only to establish good sight-lines and hence enhance visual communication, which Zagorski-Thomas (2014) has noted is a key factor in record staging, but also to sonically represent the relationship of musicians in the room. Without acoustic baffling, and through use of condenser microphones (normally AKG $451 \mathrm{bs}$ ) the sound of all string instruments could be heard on all microphones. This phenomenon is known as 'bleed' by audio engineers, and is often considered a problem due to lack of isolation between parts. However, in this case it was something we strategically pursued due to the way it creates a sense of three-dimensional space and of multiple voices in a room. As Zagorski-Thomas has noted, one of the most important aspects of the "staging" of recorded sound is the creation and perception of space. Much spatial staging can suggest images in the listener's mind, such as the relationships between the performers (Zagorski-Thomas 2014: 39). While this is more commonly achieved at the mixing stage through judicious use of effects and panning (Zagorski-Thomas 2014: 73), we aimed to create the perception of intimacy through decisions made at the moment of recording. This also had the effect of creating a thick, dense backdrop to the stories, rather than a clear spatial picture.

We aimed to capture something of the feel of Bankstown itself through engineering decisions. Our experience of Bankstown was as a dense, contested, urban, multi-dimensional, multi-lingual space, with varying voices and sounds rising and falling in volume. This experience guided our decision to record live and to capture bleed between instruments, and the staging of sonic space on the record reflected the actual use of space in Bankstown. Vad (2017) has observed the recent "spatial turn" in popular music studies. Such a turn connects to Foucault's idea of space as a critical concept, to rival that of time, implying in turn ways in which 
modern record production might create virtual spaces or heterotopias. These recordings also provide a specific example of how this might occur in practice. For instance, multi-channel recording technologies afford record producers new ways of representing space, and in our case, we chose to represent space through methods which eschewed isolation and manipulation in favour of bleed, saturation and liveness.

\section{Conclusion}

These two songs, and Songs From Northam Avenue in general, are poetic responses to Bankstown. These responses were the result of careful and repeated listening listening to stories, listening to the sonic and cultural environment, and listening to local musicians' ways of playing and recording. The research behind this record suggests a number of concrete strategies for responding to place in song which may be useful to other practice-based researchers, songwriters, composers, arrangers, and producers working in this field. These include: basing lyrics on conversations with local residents; responding to the landscape through harmonic and structural choices; reflecting something of the lived and heard culture of the place through instrumentation; collaborating with local musicians and basing these collaborations around improvisation and spending time together away from rehearsals; and a recording technique that aims to sonically capture the place itself. These strategies are particularly relevant for capturing something of the spirit of a diverse urban space through intercultural music-making. In doing so they suggest a $21^{\text {st }}$ century and globally-connected approach that is applicable to urban and suburban places elsewhere. These recordings also show that music can offer a layered, embodied, poetic response to place.

\section{Endnotes}

${ }^{1}$ Urban Theatre Projects is an innovative theatre company that seeks to tell contemporary Australian stories, from their base in Sydney's south west, through different types of artistic practice. They frequently team artists with non-artists such as local residents and businesses. See http://urbantheatre.com.au/

${ }^{2}$ See for example the discussion of You Am I's albums

http://messandnoise.com/features/4404714 (accessed 11 December 2017).

${ }^{3}$ See: http://profile.id.com.au/bankstown/language and http://www.sbs.com.au/news/map/where-australias-immigrants-were-born-sydney ${ }^{4}$ https://www.creativespirits.info/aboriginalculture/people/aboriginal-population-inaustralia (Accessed 11 December 2017).

${ }^{5}$ A Google search with the search terms "Daily Telegraph" (Australia's best-selling newspaper) and "Bankstown" will provide a snapshot of the type of articles I mean.

${ }^{6}$ It should be noted that there is also a variety of literal Indigenous music in Bankstown, however this was not something I attempted to recreate on the album.

\section{References}

\section{Bibliography}

Ahmad, M. 2013. Western Sydney Deserves to be Written About. The Guardian, 18 July. https://www.theguardian.com/commentisfree/2013/jul/18/western-sydneyrepresentation-community. Accessed 13 December 2017. 
Barleet, B. 2016. The Role of Love in Intercultural Arts. In P. Burnard, E. Mackinlay and K. Powell Eds. The Routledge International Handbook of Intercultural Arts Research. London: Routledge: 91-101.

Bayley, A. and Nooshin, L. 2017. Whose Difference? Whose Multiculturalism? British Forum for Ethnomusicology One-Day Conference: 'Listening to Difference': Music and Multiculturalism. Cambridge: University of Cambridge, 21 October 2017.

Bennett, A. 2005. Music, Space and Place. In S. Whitely, A, Bennet, and S. Hawkins Eds. Music, Space and Place: Popular Music and Cultural Identity. Farnham: Ashgate: 2-7.

Carfoot, G. 2016. Enough is Enough: Songs and Messages about Alcohol in Remote Central Australia. Popular Music 35(2): 222-230. http://dx.doi.org/ 10.1017/S0261143016000040

Cohen, S. 1995. Sounding Out the City: Music and the Sensuous Production of Place. Transactions of the Institute of British Geographers 20(4): 434-446. http://dx.doi.org/ $10.2307 / 622974$

Hage, G. 1997. White Nation: Fantasies of White Supremacy in Multicultural Society. Sydney: Pluto Press.

Hage, G. 2011. Multiculturalism and the Ungovernable Muslim. In R. Gaita Ed. Essays on Muslims and Multiculturalism. Melbourne: Text: 165-186.

hooks, b. 1992. Eating the Other: Desire and Resistance. In b. hooks Black Looks: Race and Representation, Boston: South End Press: 21-40.

Kassabian, A. 2004. Would You Like Some World Music with your Latte? Starbucks, Putumayo, and Distributed Tourism. Twentieth Century Music 2(1): 209-223. http://dx.doi.org/ 10.1017/S1478572205000125

Klopper, C. 2010. Intercultural Musicianship: A Collective and Participatory Form of Music Exchange across the Globe. Australian Journal of Music Education 2010(1): 4857.

http://search.informit.com.au/documentSummary; dn=691228316379466;res=IELHSS

Accessed 15 July 2017.

Macarthur, S, Crossman B and Morelos, R. 2007. Intercultural Music: Creation and Interpretation. Sydney: Australian Music Centre.

Le Menestrel, S. and Henry, J. 2010. "Sing Us Back Home": Music, Place, and the Production of Locality in Post-Katrina New Orleans. Popular Music and Society 33(2): 179-202. http://dx.doi.org/ 10.1080/03007760903086151

Mitchell, T. 2013. New Zealand Glimpsed through Iceland: Music, Place and Psychogeography. Musicology Australia 35(1): 41-66. http://dx.doi.org/10.1080/08145857.2013.761099

Mitchell, T. 1996. Popular Music and Local Identity: Rock, Pop and Rap in Europe and Oceania. London: Leicester University Press.

Newman, D. 2003. On Borders and Power: A Theoretical Framework. Journal of Borderlands Studies, 18 (1): 13-25. http://dx.doi.org/10.1080/08865655.2003.9695598

Paget, D. and Roscoe, J. 2006. Giving Voice: Performance and Authenticity in the Documentary Musical. Jump Cut: A Review of Contemporary Media 48, winter. http://www.ejumpcut.org/archive/jc48.2006/MusicalDocy/index.html Accessed 13 December 2017.

Plasketes, G. 1995. Cross Cultural Sessions: World Music Missionaries in American Popular Music. Studies in Popular Culture 18(1): 49-61. http://www.jstor.org/stable/23413757 Accessed 23 April 2017.

Simic, Z. 2008. What Are Ya?: Negotiating Identities in the Western Suburbs of Sydney During the 1980s. Journal of Australian Studies 32 (2): 223-236. http://dx.doi.org/10.1080/14443050802056748

Smith, B. 2017. Youth Group's Toby Martin on his New Solo Album and Being an Outsider in Western Sydney. The Guardian, 21 February 2017. https://www.theguardian.com/music/2017/feb/21/youth-groups-toby-martin-on-hisnew-solo-album-and-being-an-outsider-in-western-sydney Accessed 13 December 2017. 
Spitzer, W. 2017. Vulnerability, Trust and the Social Dynamic in Creative Musical Collaboration. Tracking the Creative Process in Music, TCPM $4^{\text {th }}$ Biennial Conference, Huddersfield: University of Huddersfield, 14-16 September 2017.

Stokes, M. -

(Ed.) 1994. Ethnicity, Identity and Music: The Musical Construction of Place. Oxford: Berg.

2004. Music and the Global Order. Annual Review of Anthropology 33: 47-72. http://dx.doi.org/10.1146/annurev.anthro.33.070203.143916

Trulsson, Y. and Burnard, P. 2016. Insider, Outsider or Cultures in-between: Ethical and Methodological Considerations in Intercultural Arts Research. In P. Burnard, E. Mackinlay and K. Powell Eds. The Routledge International Handbook of Intercultural Arts Research. London: Routledge: 115-125.

Vad, M. 2017. Perspectives from the Spatial Turn on the Analysis of Space in Recorded Music. Journal on the Art of Record Production, 11. https://arpjournal.com/perspectives-from-the-spatial-turn-on-the-analysis-of-space-inrecorded-music/ Accessed 14 September 2017.

Zagorski-Thomas, S. 2014. The Musicology of Record Production. Cambridge: Cambridge University Press.

\section{Discography}

Cooder, Ry and Vishwa Mohan Bhatt. 1992. Meeting by the River, Water Lily Acoustics, US.

Darkstar. 2015. Foam Island, WARP, 1 October, UK.

Farka Toure, Ali with Ry Cooder. 1994. Talking Timbuktu, World Circuit, 29 March, UK. Hawley, Richard. 2005. Coles Corner, Mute, 5 September, UK.

Kahane, Gabriel. 2014. The Ambassador, Sony Classical Records, 3rd June, US.

Magnetic North, the. 2012. Orkney: Symphony of the Magnetic North, Full Time Hobby, UK.

Magnetic North, the. 2016. Prospect of Skelmersdale, Full Time Hobby, 18 March, UK. Martin, Toby. 2017. Songs From Northam Avenue, Ivy League Records, Australia.

Simon, Paul. 1986. Graceland, Warner Bros, 25 August, US.

Sirocco. 1989. Port of Call, Jarra Hill, 8 November, Australia.

Springsteen, Bruce. 1982. Nebraska, Columbia, 20 September, US.

Stevens, Sufjan. 2003. Michigan, Asthmatic Kitty, 1 July, US.

Stevens, Sufjan. 2005. Illinois, Asthmatic Kitty, 4 July, US.

You Am I. 1996. Hourly Daily, rooArt, 1996, Australia. 